This is a pre-copyedited, author-produced PDF of an article accepted for publication in Sociological Research Online journal, following peer review.

The published version:

Annebella Pollen, 'Shared Ownership and Mutual Imaginaries: Researching research in Mass Observation', Sociological Research Online, 19 (3), 9, first published 15 August 2014 can be found here:

http://www.socresonline.org.uk/19/3/9.html

DOI: $10.5153 /$ sro.3317

\title{
Shared ownership and mutual imaginaries: \\ Researching research in Mass Observation
}

Keywords: Mass Observation, research, method, methodology, intersubjectivity

Annebella Pollen

\section{ABSTRACT}

The methodologies that might be best used to interpret Mass Observation's distinctive research resources have tended to be considered on a case by case basis by individual researchers and have rarely been the subject of concerted, dedicated scrutiny. During 200910, however, the University of Brighton research network Methodological Innovations: Using Mass Observation (MIMO) brought together 150 international academics, archivists, writers and artists to debate and share methods for analysing the materials of the post-1981 Mass Observation Project (MOP) in particular. Through discussion lists and events, a range of disciplinary approaches were brought to bear on core topics of methodological concern, from the 'representativeness' of the writing panel and discussions about sampling and extrapolation, through to debates on the very nature of Mass Observation (MO) material and how it might be defined. This paper draws on these productive discussions and brings them together with previously unanalysed insights and reflections on similar issues by MOP correspondents, for as Sheridan, Street and Bloome (2000) have argued, 'Mass-Observers themselves are as reflective and thoughtful about issues raised, methodological and theoretical as well as ethical and political, as the academic commentators.' Using responses to the MOP directive, 'Being Part of Research' in parallel with MIMO discussions, this paper draws new connections between contributors and users, as two of the core constituent bodies involved in the production of meaning in MO. Through comparative analysis of each groups' discussion of methodology, this paper highlights the often unarticulated but ultimately interdependent relationship between contributors and their readers in order to reveal their shared understandings, mirrored concerns and mutual imaginaries. 


\section{Comparative perspectives on MO: Contributor and user symmetries}

The definition and purpose of $\mathrm{MO}$ and the potential utility and validity of its distinctive materials have been debated extensively over its 75-plus year history (for just three examples, see Hinton 2013; Hubble 2010; Sheridan et al. 2000). As the project's own methods for acquiring content have changed substantially over the life of the organisation according to shifting personnel, research agendas and funding requirements (Hinton 2013; Sheridan et al. 2000; N. Stanley 1981; L. Stanley 2001), so too have the approaches taken to its use and interpretation. As a unique and diverse body of material on a vast scale, informed by the original founders' eclectic interests in poetry, psychology, anthropology, sociology and art - as well as changing academic fashions over several generations - the methodological pluralism (Goot 2007) of the circumstances of MO's generation inevitably and fittingly opens its results to a diverse range of interpretive methods (Pollen 2013). MO's content ranges across a wide variety of forms, from questionnaire replies and poetry to life writing and photography, and has consequently attracted a broad range of researchers who each bring their own particular disciplinary interpretive tools to the material.

In 2009-2010, the University of Brighton funded a year-long project, Methodological Innovations: Using Mass Observation (MIMO), led by Louise Purbrick and Mark Bhatti, with Annebella Pollen as Research Fellow and MO Archive Director, Dorothy Sheridan, as advisor. This established a research network of over 150 international members from across disciplines and professional boundaries for the purpose of sharing, debating and evaluating cross-disciplinary methodological approaches to the understanding of the post-1981 Mass Observation Project (MOP), in particular. Through a lively email discussion list, two archival workshops and a conference entitled Engaging Mass Observation: New Perspectives on Contemporary Material, researchers (including artists, curators and writers as well as sociologists and historians) came together to examine the variety of disciplinary methods by which the often complex and very particular MO materials could be utilised and interpreted. This involved revisiting thorny issues such as the 'representativeness' or otherwise of the writing panel (and, indeed, the various interpretations of the meanings of this term); debating how MO documents may be defined (variously as social science, as life writing, as documentary, as art, and so on); and examining practical strategies for dealing, sensitively and appropriately, with the expansive mass of diverse, subjective, longitudinal and qualitative material. Through sometimes heated debate, disagreement and questioning, newer and more experienced researchers of $\mathrm{MO}$ reflected extensively on its character and value, its problems and potential. Enduring methodological concerns were revisited, attacked from new directions, chewed over and sometimes spat out. Researchers shared tactics and asked guidance of one another; they critiqued existing methods and suggested new means of approach. 
Core themes emerging from this data were analysed in Pollen (2013), in conjunction with a review of over 50 publications that had utilised post-1981 MOP material to examine how and why it has been deployed, characterised, sampled and interpreted. This paper takes a new approach to analysing the discussions generated in the research networks of the MIMO project by exploring the way concerns about methodology intersect with those of Mass Observers. As will be shown, particularly in relation to MOP's methods for recruitment, data collection and organisation, and additionally in relation to the methods and methodologies adopted for interpretation, the concerns of the contributors and the users can closely mirror one another. Aligning responses to the 2004 MO directive 'Being Part of Research' with the 2009-10 reflections of the researchers, this article assesses the attentive and sometimes anxious care that self-reflective MO researchers can apply to their use and analysis of MO writings, in conjunction with correspondents' own reflections on the purposes of their contributions and how they imagine them being received and employed.

This interest in contributor/user symmetry was inspired by my own particular condition as a very short-lived MOP correspondent in the early 1990s, and then my later move to the 'other side' of the archive, as a researcher, some fifteen years later. MO's contributors and users, even when they are not one and the same, may not be easily divided into respondents and interpreters, researchers and researched. To do so would be to pass over the complexities of their sometimes multiple identities and what Sheridan (2010:4) has described as 'the blurred distinctions between investigators, informants, collaborators and data subjects' that have been a part of the project's distinctive and complex identity since its earliest days. Mass Observers are not merely subjects of study but are themselves observers and interpreters of their own worlds and readily reflect upon their contributions as they make them. The intimate nature of the resulting material (where anonymous, first person and often candid material is shared) means that researchers may be brought into closer range with their 'data' than might happen in other social research, yet the concealed identity of observers also requires some imaginative investment on the behalf of the researcher who may want to draw out larger stories from the account. The individual perspectives of the two parties come together in a dialogical relationship through the archival encounter, where contributor and recipient roles are acted out and points of convergence are established. These roles are ultimately interdependent and mutually shaped; one group cannot be properly understood without acknowledging and analysing the needs and expectations of the other.

\section{Reflecting on MO: Researching research}

Mass Observers are asked to provide reflective, subjective appraisals to the topics in every directive (the questionnaires that are issued three times a year on a range of themes from major international and political affairs to domestic habits and dreams). More rarely, observers are also asked to reflect on the project itself. The most substantial of these 
enquiries took place in 1991 where the entire directive was dedicated to MO and to Mass Observers' purposes for taking part. This material formed the basis for a one-year ESRCfunded project, 'Literacy Practices and the Mass Observation Project', undertaken by Brian Street and Dorothy Sheridan with David Bloome, and resulted in a range of outcomes including some of the most important and widely-referenced publications on the post-1981 Mass Observation Project and its methodology (Bloome et al. 1993; Sheridan 1993a, 1993b; Sheridan et al. 2000). More recently, in 2010, as a means of gauging responses to changing communication practices and the challenges and potential of moving MOP online, archive staff issued a 20-point questionnaire that asked observers for mostly practical details about preferences in directive format and style, their motivations for participation and continuation and finally their thoughts on anonymity and digitisation.

In the autumn of 2004, a more substantial discursive and directive asked observers to consider, at length, their feelings about being part of research. Over a page and threequarters of a two page directive, correspondents were asked to recall their experiences of researching and being researched, and a particular headed section asked for 'Reflections on Mass-Observation'. These questions asked:

- Does this feel like taking part in social research? Please explain.

- When you write replies to the directives do you consciously think about the people who read what you write and use it in their research?

- Have you ever wanted to know more about the people who use your replies in their research?

172 replies were received to the directive as a whole and 119 of these responded directly to the reflective section on MO; this material is drawn on here. The central concerns of the responses focused firstly on classifying MO. Was it research or something else? Contributors considered the ways in which it differed from other techniques, largely in relation to commercial market research. As such, they reflected on its merits and shortcomings as a historical and social research resource. This led to considerable appraisal of $\mathrm{MO}$ as a tool, including reflection on the method and practice that ought best be employed in its interpretation by readers and researchers. These aspects - which implicitly asked contributors to reflect on MO's research methods and the methodological approaches that might be used in the interpretation of the resulting material - closely intersected with researchers' responses to similar debates generated and examined in the context of the MIMO network; these intersections will be explored below.

The three directive questions under scrutiny were ideally phrased to open out a range of perspectives, as the observers were firstly asked to provide their own opinions and then to second-guess the opinions that others may have of them. The distinctive dialogical formation of this aspect of the directive can be analysed according to Gillespie and Cornish's 
(2009) intersubjective system of 'direct perspective', 'metaperspective' and 'metametaperspective'. The questions first ask observers where they situate themselves in research, thus providing a direct perspective. The second question asks the observers to acknowledge that they are being researched and that their contributions will be used, thus creating an opportunity to reflect on their invisible readers, as a metaperspective. Finally, in asking observers to consider their researchers' positions, the final question implicitly asks for a meta-metaperspective; indeed, many respondents interpreted this as an invite to stand in their researchers' shoes and see through their eyes; as D156, a florist from the south of England put it, in her response: 'What must they think of me?'

\section{Imagining the Mass Observers: Individuals or categories?}

In MO there is a great deal of mutual imagining between contributors and those who read the contributions. Although archive staff regularly produce bulletins that inform researchers and contributors of developments in the archive, promote publications that have utilised the contributed material and publish selected extracts from directive responses, contributors and researchers will rarely meet. As any user of the MO Archive knows, contributors to the MOP have their anonymity protected by the use of a code number. Although all are required to provide a self-portrait in the form of a brief selfdescription that includes gender, age and region and may extend to occupation, social class, marital status, sexual orientation and beyond, the person of the writer is revealed only (if often extensively) through the content of his or her writings, and thus may appear hard to grasp without longitudinal immersion in their contributions over many directives.

As will be discussed below, anonymity is a quality that is valued by the majority of contributors, but for a reader of an anonymised contribution, it is sometimes tempting, and even necessary, to fill the gaps around a contributor's statements. This may be done in a number of ways. It may be done by offering the observer a new identity - as with Raisborough and Bhatti (2007), who dwelt at length on the words of a single contributor, and named her 'Joy' to humanise her code number - or through finding other means of engagement, for example, by looking for what may be revealed between the lines of contributors' text. Design historian Purbrick has argued:

Mass-Observation writers are met through the materiality of their writing. They are seen in the wobbly script of an elderly person on note papers, the capitals used by someone who wrote little for a living, the mistake-free typing of a woman who worked as a secretary all her life, the rapid writing of a busy mother. (Purbrick 2007: 170)

Others have sought out signs of personality in the material dimension of submissions for their research into family secrets, and read presentational form as revelatory (Swales 1990). 
Harrison and McGhee read off smudges on contributors papers as signs of spilled drinks and 'unrestrained tears' (2003: 33). For those in search of additional elements of disclosure, these material aspects may offer unspoken but suggestive clues in addition to that which is revealed through the written word.

Most commonly, however, as researchers look across the material for patterns, contributors are understood in relation to their readily available demographic characteristics - age, class, gender and geography. As Pollen (2013) observes, how Mass Observers might be understood is reflected on by researchers who may seek to characterise the panel as typical or unique depending on their outlook. Its particular demographic leanings may be privileged by those seeking out particular constituencies for research purposes. The characteristics of the panel as self-selecting, historically conscious, civicminded and / or enthusiastic about writing can help researchers build correspondences between projects and participants in studies that aim to access information about, for example, volunteering, community history, literacy or indeed, being part of research. The demographic make-up of the panel - generally dominated by older rather than younger contributors, with a greater appeal to women rather than men, and with a population more commonly located in the south east of the UK than the north west - may appeal to researchers in pursuit of, for example, gerontological experience, particular gendered perspectives or geographical points of view. Researchers who turn to MO in pursuit of a mass overview may wish to defend its representative status and even to extrapolate larger social conclusions from the material than it can support. Such researchers may regret that the contributors are not larger in number or more statistically diverse in make-up.

Concerns about 'representativeness' and generalizability - the extent to which one can infer larger tendencies from individual accounts or consider the panel as a cross-section of British society - were central to MIMO discussions. A tension between treating observers as distinct individuals and the need to draw out a larger picture was a regular discussion point in MIMO debates. This required reflection on who Mass Observers actually are; are they individuals speaking for themselves? Are they speaking on behalf of particular constituencies (the working class, the retired, the silent majority)? To what extent can their contributions be read as representative of a larger view?

While the tracking of collective patterns might offer safety in numbers and statistical security, both researchers and contributors can be cautious about this approach. Ben Highmore, for example, as a cultural historian who used MO extensively for his book Everyday Life and Cultural Theory (2002), explored this point on the MIMO discussion list. He proposed that examining the particular responses of correspondents would be to disaggregate the collective archive of Mass Observers back into its individual characters rather than reducing them to mass patterns, in the spirit of the original project. As he argued, 'In the best writing that uses $\mathrm{M}-\mathrm{O}$, the particularity of respondents' quotes are 
never held hostage by overriding arguments'. He suggested that as a researcher he felt a duty to dignify unknown contributors' individual documents with 'the same sort of attention that might be lavished on the writings of a famous author' (MIMO discussion list, 8 October 2009).

This approach, whereby one focuses on the individuality of the writer rather than the patterns into which they might be pressed, was also discussed by James Hinton, a historian who has used MO as a means to examine cultural histories of wartime, and also researched the history of the organisation itself (Hinton 2010, 2013). He argued:

The more you try to use the writing of individual respondents as a basis for generalisation, the more you are forced to put to one side precisely what it is that MO can best reveal: individuals struggling to make sense of their lives. [...] Individual subjectivity is always more complex than generalisations about the life of the group. Every person does it differently; and the more one knows about any particular individual, the less they can be used to illustrate some more general experience or theme.

Hinton also noted that by approaching the contributions as individual biographies, issues of generalisation and representativeness were not side-stepped as 'the texts themselves, read alongside the historiography of the period, threw up certain common themes' across individual lives. Nevertheless, Hinton observed 'the surprising ways in which the complexity of individual lives breaks out of any analytical categories with which you might try to capture experience'. (MIMO, 8 October 2009) To this point, sociologist Anne-Marie Kramer responded with a pithy observation about the shortfalls of using correspondents of mere examples of theory:

People are not simply the sum of the categories into which they fall. That the sum of their experience cannot be captured by those categories in $\mathrm{MO}$ is neither a problem with the way the material is gathered nor a problem with the people who write for $\mathrm{MO}$, but is to my mind, a problem with assigning meaning to the categories themselves over and above their analytical utility.

As she goes on to say, 'I am much more interested in what MO can tell us about people's personal, intimate lives. And that is a far messier business than can ever be captured in the term "representative".' (MIMO, 9 October 2009) In the debates over the singular and the collective, the need to focus on the individual won out among MO researchers, even if the identity of that anonymous and partly concealed individual may be hard to capture.

Capturing the identity of those who write for $\mathrm{MO}$ is, of course, keenly overseen by the archive management, who actively build and maintain the relationships with the individuals 
that enable the larger project to exist. As a result of regular and reflective analyses of the age, class, gender and geographical make-up of the panel, archive staff implement systems to manage the demographic to attract and retain less well-represented groups (younger men, for example). Although it may be convenient to refer collectively to 'Mass Observers', researchers in search of collective patterns may effectively reduce contributors to their demographic characteristics, thus flattening individuals into a mass. Mass Observers, when looked at across the cohort, may indeed have certain tendencies. They may be people with an opinion that needs to be heard, for whom MO is a soapbox; they may be somehow disenfranchised from conventional education and find in $\mathrm{MO}$ an opportunity for selfimprovement; they may be altruistic or community-minded, and use $\mathrm{MO}$ a means to participate in a meaningful social and historical enterprise, yet there is no such thing as an average observer. Despite popular and reductive accusations to the contrary, 'little old ladies' (MIMO list discussions, 29 July 2009) or 'middle England' (Black and Crann 2001) they are not.

Sheridan - uniquely positioned to reflect on the particular and distinctive characteristics of mass observers, as she has more than thirty years' experience in recruiting and managing them - is at pains to point out that despite some researchers' desire for statistical, nationally representative 'purity', contributors can never be made to inhabit some kind of neutral statistical representative role outside of the project; they are shaped if not created by it and the contributors (and their contributions) reflect its construction. As she puts it:

Who they are depends on what they think $\mathrm{MO}$ is; what they think $\mathrm{MO}$ is depends on how the MOP is represented - by the media, through our direct correspondence with them and by the outputs of researchers who use their writing. Who they are depends on how what they do fits with the ethos of the MOP, with their feelings about writing, about social research, and volunteering and civic duty, about the past and the future and about their constructions of who their audience is. (MIMO, 2 September 2009)

This point is important for two reasons. The first is the acknowledgement of the defining role of the archive in the shaping of the meaning of MO: arguably, the third core player in the research relationship. The archive is more than an organisational backdrop or a mere physical space; it is a group of named staff whose labour in founding, promoting, organising and interpreting the overarching project is often overlooked (Sheridan 2012). The second aspect of Sheridan's statement that is most relevant here is the reminder that $\mathrm{MO}$ contributors are partly produced by their users; who they are and what they contribute is in part defined by what researchers ask and what they think their audience wants.

\section{Imagining an audience: Mass Observers on their readers}


Sheridan has observed that writing for $\mathrm{MO}$ is 'based on, and validated by, an assumption of readership' (1993a: 21). MO writing is always 'for' and 'to', even if its intended audience and purpose is sometimes hard for contributors to articulate. Shaw has suggested that even outside of the opportunities when correspondents are asked to reflect on the destination for their contributions, they "need to imagine an "other" or "others" to whom they address the writing'. This, she argues, makes 'projection and a desire to create something wanted the core of writing for M-O' (Shaw 1998: 4). In Autumn 2004, correspondents reflected at length on the person to whom their writings might be addressed, and engaged in playful acts of imagination when thinking about the researchers who jointly commission the questions that they are asked and then use the writings that they submit. Some reflected on the interconnected relationship between the two parties, where researchers were explicitly understood by some as central and meaningful to their own role, while others denied all interest in their recipient and saw their writings as independent constructions. The following section clusters responses that represent the dominant themes on these topics that emerged from the directive.

Several participants relished the way that MO allows for non-judgemental communication, particularly among those who do not have this opportunity elsewhere. As S1399, describing herself as a Tunbridge Wells housewife, put it, 'I have to sit down and listen to my 93 year old mother in law Mon-Fri + she's so opinionated +always right. When my husband's home, I can't have any views myself either, so at least I can tell Mass Obs'. N1592, a retired social worker from Hebden Bridge, states, 'It's a golden opportunity to say what I like without being contradicted.' The distance between writer and reader was also relished by contributors who found the format freed them from having to consider anyone else's needs. M3147, a postmistress in North Wales observed, 'I know that I can say what I want without fear of meeting anyone who reads this'. C3006, a town planner from Gloucester argued, 'When I write for $\mathrm{MO}$ I am attempting to crystallise my thoughts and feelings as accurately as I can, not to please anyone, or to try to achieve an outcome of some specific nature, but to record how I see particular issues, and how I feel about them [...] There is no need to consider anyone's feelings in making these responses.' H1541, a writer in Central Scotland asserted, ': 'I don't consciously consider those who may have set the Directive, and certainly never those who might use the material at a later date [...] I regard it as a fairly dispassionate activity, in that as I don't try to satisfy either originator or user, I solely attempt to give a straightforward response.'

A core cluster of contributors claimed that they did not think of their readers, such as C41, a Shetland housewife, who wrote, 'I don't consciously think about the people who read it and use it. I think of it as a bit like writing a letter to the archive.' Some deliberately employed this way of thinking as a convenient strategy of avoidance, such as D156: 'I prefer to think of it as going into a huge computer or archive than imagine individuals picking up a piece of paper and reading it out to others! Of course I know that individuals are at the core 
of MOA but it's easier to think of it as an 'institution'.' MO users were amalgamated among these kinds of conceptualisations as 'an amorphous mass' or 'a disembodied audience, no one in particular'.

For some, this separation between what they provide and what use is made of it was maintained as a statement of independence, such as in the words of D2589, a retired radiographer from Pinner: 'When I write - I write how I feel + react to the questions asked how the readers react is their problem!' or F218, who simply describes herself as 'female': 'I have freely given what my inner mind wishes to. I have never been swayed by what Mass Observation may think of me'. For T3155, a Municipal Mechanic from Exhall, 'Writing this is almost like writing an anonymous letter I can say what I want good or evil, agree or disagree. To know the reader in my opinion would make this a two way conversation in which we could disagree or be swayed by the others opinion - No thanks'. C2053, a selfemployed clerical worker from Attleborough, stated, 'I prefer to remain in ignorance. To have more knowledge, might, consciously or not, affect the way I responded. Ignorance is bliss in this instance.'

Several correspondents suggested that writing for MO provides self-satisfaction and even therapeutic value. As such, the researchers' requirements were outside of the equation. As B3010, a charity manager from Jersey stated, 'No, I don't think about the researchers. I write for the pleasure of writing, and for the interest in examining my views.' B3154, a financial advisor from Stoke on Trent, claimed, 'I was mostly conscious of a space to think through something for myself and that it may be read by someone else or used in research seemed almost incidental.' M3147, a Welsh postmistress reflected:

sometimes when I'm upset, worried, angry I need an outlet and before doing this I would write a letter to my friend but it would rarely get posted, it would end up on the fire and I would feel better as I've got it out of my system. ... I have a terrible habit of turning my anger on myself so this diary / directives / notes etc is wonderful self-help treatment.

Others claimed that researchers were so far from them that their presence was irrelevant. G2134 a retired civil servant from Surrey insisted, 'I don't think much about who's reading - I have so little idea of what they want it for that there's no point trying to write for a particular audience'. Some even claimed that the audience was not so much imagined as imaginary. G1041, a retired librarian from Purley said, 'No, I don't think about the people who read what I write for M-O (are there any?) who use it in their research. I don't want to know more about them as I don't believe they really exist!' A significant proportion of other contributors, however, argued that the figure of the reader loomed large as they wrote. As K1515, a retired civil servant from Orpington put it, 'I am always conscious of who might read my answers.' This can shape how Mass Observers communicate as well as what they say. For F3137, from Norfolk, who describes her own occupation as a researcher: 'I find when I'm writing my replies that I do think about the 
researchers, and I try to write carefully so they will understand the point I'm trying to make.' For some, of course, to be read by a researcher is to be validated. As B1509 a retired surveyor from Oxfordshire noted, 'a year or two ago I was rather pleased to read a newspaper article which I immediately recognised as being on a subject which I and others had written about.' B1771, a retired secretary in Surrey put it even more explicitly: 'The thought that a researcher might find some part of it useful gives me a warm glow.'

The utility of contributions is a notable theme among Mass Observers. B3133, a student from Birmingham, wrote, 'I keep thinking, I wonder if that sentence will be useful for someone looking for a certain topic and hope it will'. This concern suggests that Observers are involved in second-guessing what is wanted from their contributions, and the range of what could be described as the functionality of the writing goes beyond any tacit understanding of the provision of data; many write to make a point, change a mind, raise a smile or otherwise move their reader. M2986 from East Grinstead, an invigilator in local school, confides, 'I hope that those who use them will find my pieces useful, sometimes poignant, sometimes funny, and that I have a voice that is relevant.' H1543, a retired local government officer living in West Sussex states, 'When I write replies to the directives do I consciously thing about the people who read what I write and use in their research? Yes and I try to give them something to think about.' Finally, C2570, a housewife, reflects, 'I do just hope that some sentence of mine will affect their thinking a little bit so that it has not been a waste of time.'

Even if Mass Observers claim to be writing for themselves, Sheridan has also noted that 'versions of the self constitute the imagined reader.' These extended selves may be perceived as 'people like them', interested in writing, in history, in ordinary people's lives, or versions of self recast as descendants, granddaughters or great-granddaughters (1993a: 21). The recipient may therefore be understood as some kind of mirror. When pressed, in 2004, readers are imagined in a range of ways, from the intimate to the distant. Readers may be sympathetically similar at one end of the spectrum, and quite alien at the other. As R2065, former administrator from Mitcham, Surrey puts it, of the continuity between writers and readers: 'I never think about the people who read these outpourings. [...] I just accept the fact that they're funny that way, just as we are a bit funny in the way we churn out these offerings.' Similarly, R2143, a retired surveyor from Hampshire admitted, 'I have felt a mild curiosity [about the people who use MO writing] from time to time, not so much about their end product as about the circumstances which led them to ask the questions. Some of them must be as odd as I, from time to time, am said to be.' Of those who perceive a close relationship between writer and reader, there can be some idealising of their audience. R450, a retired builder from East London, says that when he thinks of the people who read his replies: 'I find myself seeing people of intelligence and insight and overall humane spirit that have reached the apex of learning and are in no way part of the establishment's jobsworth sycophants'. R2143 writes, again, 'I do feel that my opinions may be used to devise social philosophies. But those opinions are, I do believe, from a much lower level in 
the chain of experience and reasoning than are the assumptions on which the run of research questions are based.'

Some Mass Observers are more suspicious about the character of their readers. C1191, a carer from Limavady, says: 'I would like to know what sort of people read this stuff. Are they like me or are they academics or published writers? Perhaps they float about Cambridge and wear peculiar clothes? The mind boggles.' A sense that readers are likely to be strange is revealed in the distinction set up by $\mathrm{C} 1832$, an office worker from Birmingham. She says: 'I have thought from time to time I wonder what the people who read my directive are like [...] are they academics or just ordinary people?' It is notable that there is a strong antipathy towards academics among some respondents, which is interesting given that these are likely to be their main audience. As just a couple of examples, K1515, the retired civil servant from Orpington notes, 'I have strong doubts about being used as a convenient source of information by researchers. It saves them a lot of spade work; I wonder how much plagiarism occurs'. F2218, a retired NHS supplies officer from the rural North East admits, 'I do not think about the use made of my replies to your questions because I have a low opinion of researchers and statistics!'

In many cases, evident in the 2004 directive, and in the 2010 directive which enquired into why $\mathrm{MO}$ writers write, correspondents are documenting the present for a latent future, for a time when they perceive that everyday occurrences and observations will have been made strange and fascinating by the passage of time (and perhaps their readers may have become more interesting too). Partly informed by the dominance of wartime material in media representations of MO, from Victoria Wood's Housewife 49 television drama to Simon Garfield's popular publications of MO diary extracts, and despite regular updates on recent research activity in the MO Bulletins, many imagine that their words will be mothballed for some unspecified future date. P2957, a personal assistant to a head teacher notes: 'I've never really thought before about who reads these replies. I think I must have imagined that they all go in a safe somewhere until someone digs them out in thirty years' time!' B1509, the retired Oxfordshire surveyor, similarly observes, 'I must admit that I do not give much thought to the researchers, more usually I have visions of the filing away of reports, the microfiche and the thoughts that it might be there in a hundred years for a researcher to pull out and make use of.' For some, the idea that they might contribute to the making of history was a founding rationale. B786, a secretary from Devon, admits:

This is why I joined the project in the first place - I liked the idea that one day something I had written, recently or many years ago, could be useful or of interest to future researchers. I try to write with this in mind when replying rather than for today's researchers. 
This emphasis on the temporal mode of the future anterior - where contributors reflect on future imaginary researchers looking back on how things used to be - led to some intriguing metaperspectives and meta-metaperspectives. D156 wrote:

I get a thrill of sorts to think this could be read by someone in years to come, would they be trying to picture me all those years ago sitting at a computer typing out each letter one at a time. Where would they picture me, in a cosy lounge? [...] Would they be trying to picture my face, am I trying to picture theirs?

Some take this imagined relationship even further. $\mathrm{H} 1745$, who describes herself as a $54-$ year-old widow and writer from London, admits:

I do have what I suppose you'd call a 'fantasy' (or 'phantasy') which involves a person from the future looking through the archives for a particular purpose and finding one correspondent's writings (I suppose it is mine, if I'm honest, and why shouldn't I be honest here?) so interesting and so resonant with their own values and thinking that they begin to read up everything that person has written and you get a sort of historical love affair building up. That, I suppose, comes partly from such books as 'Possession' and 'The French Lieutenant's Woman'.

\section{Mutual imaginaries: Projection and affect}

The passionate potential of the relationship between $\mathrm{MO}$ writers and readers has been examined by other researchers who have experienced it for themselves. Shaw, in particular, has written about this in relation to the psychoanalytic concepts of transference and counter-transference:

The M-O writers transfer their feelings, expectations, desires and images onto the Archive and its staff or the hypothetical researcher, whilst the researchers and staff, in turn, develop a form of transference and projection which surround the processes of writing for, working in and working on material in the Archive (Shaw 1998: 5)

Shaw reflects that her research method is necessarily shaped by this two-way relationship: 'If the writers cannot write about themselves without making implicit and explicit comparisons with others, then I as a researcher in the Archive cannot read the material without comparing myself to the writers' (1994: 1404). The sometimes raw and often affective quality of the writing shapes our emotional reactions to it, as researchers, and consequently the use that is made of it. A shared sense of projection fills the gaps between contributor and user, fostered in part by the intimate style and content of the writing. 
Anyone who has spent time at MO will testify to the snorts and sniffles that periodically punctuate the scholarly silence of the reading room as readers fight back giggles and tears. Just as writers may produce intensely personal and intimate, emotional and cathartic texts, as Harrison and McGhee put it, "reading the archive" is not a passive activity' (2003: 33). Purbrick is one of a number of researchers who have noted that the intimate encounter with people's lives in the space of the archive can be unsettling and even overwhelming. She argues that the relationship is not interpersonal - as 'you neither see them nor know their name' - yet the interplay of proximity and distance lends itself to revelation, and the anonymity leads to distinctive advantages for the researcher as well as the contributor:

The researcher in the Mass-Observation Archive does not see the Mass-Observation writer, is not able to identify them through their age, their dress, the colour of their skin, their accent. There may be some advantages to reading over interviewing in that it prevents the all too easy social positioning of people. Without a visual confrontation, it is more difficult to assume knowledge of a writer's identity and perhaps frees the Mas-Observation researcher of some of their prejudices about who an 'ordinary person' might be and what that person might think and say. (Purbrick 2007: 170)

Harrison and McGhee also observe that 'the absence of face to face contact' is liberating for the receiver as well as the giver. They say, 'Freed from the social conventions of interview interaction, one has permission to raise a quizzical eyebrow, "tut" quietly in disbelief, or even laugh out loud at the views being expressed. There can be done with impunity, for there is no danger of inhibiting the respondent or biasing their account' (2003: 35). And yet, for the writers, imagining their readers, it is hoped that these social conventions will be upheld. Despite the fact that many seek to entertain, amuse and even move their readers, researchers are nevertheless expected to remain dispassionate and 'balanced' (in the words of several correspondents). For P1326, a retired civil servant living near Bath: 'I like to imagine that, in the true tradition of research they [the researchers] are open-minded without pre-conceived ideas and I just hope that they do not put down my ramblings with some remark like "Silly old bag"!'

\section{Joint analysis and shared ownership: Mirroring methodological reflections}

As Sheridan and colleagues have argued, there is no monopoly on research insights in MO: 'Mass-Observers themselves are as reflective and thoughtful about issues raised, methodological and theoretical as well as ethical and political, as the academic commentators' (Sheridan et al. 2000: 102). As carefully-named correspondents, Sheridan and Holland have also emphasised that, through $\mathrm{MO}$, 'writers become participants in research rather than subjects of research' $(2003 ; 26)$. Purbrick has also noted: 'It is important to remember that Mass-Observation writers are as committed to the project of 
recording everyday life as it is lived by "ordinary people" as the Mass-Observation archivists and researchers, if not more so' (2007: 170). This investment encourages correspondents to pass judgement on the nature and content of $\mathrm{MO}$. As Sheridan notes, 'there is an element of possessiveness or ownership in the attitude to the project on the part of the correspondent. The correspondents feel themselves to be genuinely participants. It is (also) their project and they are entitled to criticise' (1993b: 36).

It is certainly true that, given the opportunity, MOP participants can be reflective on what they see as the appropriate research methods and interpretive methodologies that should be applied their own writing, even if they are not sure about how such research may be undertaken. This was particularly the case in responses to the 2004 directive, where correspondents were curious about researchers' professional practices. As H1806, a retired typesetter from Woking, stated, 'I would like to know if any skills are required before a researcher can use the archives'. B3133 mused, 'As I write everything I do, I wonder how someone will use it is their dissertations or publications and hope that they will represent me correctly'. Correspondents wonder about the appropriate sampling procedures of responses (as, of course, do researchers, who asked on the MIMO list, 'what do you do with a fifty-page-long submission?' and 'how much is enough?'). G2134, the retired civil servant from Surrey states, 'I would certainly like to know rather more about the way in which are scribbling are used and how valuable they're considered to be. Do they just pull one or two out at random or is there some more ordered manner of deciding what to use?'

Correspondents share concerns with researchers about how their contribution might fit into a larger social frame. W1893, a former food production manager, wonders 'how good they are at assembling what they find into an intelligible and truly representative picture'. He continues, 'Of course MO research may form part of a greater field of work not directly linked to the subjects we are given - all very complicated.' Contributors, even if not trained researchers themselves (and some are), are aware that there are a range of ways to extricate meaning from texts and are keen that their words are interpreted appropriately. As B3010, an office manager from Jersey stated, 'I know that the material is looked at by researchers, and perhaps our writings are translated into a form with checkboxes to create "findings", but I would hope that the researchers who use the archive have a more flexible approach.' Many are aware of the challenges presented by the particular and subjective qualities of their documents. Questions are posed in relation to its wider value as well as to method. L1691, a retired probation officer from Staffordshire muses:

Sometimes what I write seems so personal and trivial I cannot see how it can be of any use to other people. Does hand writing make it more difficult for the readers? Are scripts only read by the person commissioning the research, or is there a certain amount of 'weeding out' by administrative assistants beforehand? How much is discarded?' 
Even if convinced of its ultimate worth, correspondents may nevertheless be aware that the material may be fugitive. As R1277, a primary school teacher from Exeter, stated, 'I think I have always been aware of the importance of MO. I still regard it as a vital source of information to researchers. It's quirky, relying on the written word rather than form-filling, and this must make it more difficult'.

Just as in the MIMO discussions, contributors reflect upon the particular and distinctive methods and ethics of $\mathrm{MO}$ in relation to other research methods. $\mathrm{H} 1541$, the retired film editor from Scotland argued, 'Writing for M-O feels more like a worthwhile social research than any other form of response mostly because it is relatively unrestricted and open to something much closer to a "stream of consciousness" than a tick-box.' A1706, a Sussex artist and ward clerk states, 'Research seems to imply info is being gathered for a particular reason, whereas $\mathrm{MO}$ is much more fluid and altruistic. It is an end in itself - a completely voluntary record of matters, for its own sake.' F2218, the retired NHS officer writes, 'For MO I can set out my thoughts plainly because I do not have to tick boxes, because I can explain myself, because I have not expressed opinions which will be quoted amongst a mass of others as representative of something alien to me and because what I say is anonymously given.'

Many celebrate MO's emphasis on gathering the voices of the 'ordinary' person, while some see shortcomings in the profile of the panel, just as researchers have done. C3006, the Gloucester town planner, states that $\mathrm{MO}$ 'is important because it reaches out to ordinary people who otherwise become invisible in the future and they do form the majority of the population'. G2134 is more cautious: 'I suppose we represent a somewhat limited cross section of the community - the verbose, reasonably literate section who like to express our opinions on every possible subject'. C2654, a 62-year-old woman from Birmingham, notes, 'I am a little concerned that you have masses of replies from people like me, leaving large parts of the population unrepresented in your archive.' G1041 goes so far as to describe MO as 'statistically absurd'. L2604, an illustrator and former academic in South East England, observes, insightfully:

I joined Mass Observation because I believe in its aims and objectives. I have always hoped it provided a kind of 'history of ordinary people'. However, I have thought that it is possible that Mass Observers themselves might form a category of people who are in fact not 'ordinary'. Perhaps they are a type of person who likes to reflect on their lives by writing about themselves; thus they might be considered as being extraordinary.

\section{Conclusion: Social relationships and intersubjective encounters}


It is perhaps inevitable that MO would be conceptualised similarly by those who contribute to its content and by those who use it, as each party values the project, thinks deeply about its purpose and engages with its public face. The symmetries also underline the fact that the constituent categories are interdependent and sometimes overlapping. MO material is collectively produced and its meaning is collectively owned. As Shaw has argued, MO writing 'would not happen unless there was a place and a person to receive it so, although it is personal material, it is elicited and contained within a social relationship' (1994: 1396).

Although some correspondents deny that they write for anyone but themselves, writing to $\mathrm{MO}$ is always solicited and consequently shaped by the nature of the questions asked and the contributors' conceptualisation of the larger project. All research outcomes are, of course, the product of their particular conditions. Some writers are acutely conscious of this. As G2889, a Cambridge anthropologist states: 'We always temper our responses in recognition of an imagined audience (even perhaps in writing our own diaries).' When trying to identify what might be useful, second-guessing researchers' needs, and anticipating memories by thinking of what future historians might find interesting, the correspondents' contributions provide not only the direct perspective of the author but also a range of selfreflexive metaperspectives and meta-metaperspectives. Whether explicitly or implicitly, knowingly or unwittingly, the observers frame what they think in terms of what they think the researcher will want to read or need to know. In turn, as the MIMO debates show, researchers can think carefully about how the observer is constructing themselves. There are affective responses and emotional investments on both sides.

In the imagining of readers and the imagining of contributors, elements of projection are clearly at play. This is not to deny the validity of the data contributed, but to acknowledge the formative role of each of the players in the resulting meaning. As Clifford (1988) has observed in his classic analyses of the ethnographic encounter, the researcher becomes a part of the subject of study and shapes its results. Imagination is also a distinctive element of MO's research method (Shaw 1996); not only is this due to the particular nature of its qualitative data, which could be described as a subjective, impressionistic form of creative non-fiction, but also to do with the project's founding objectives to understand what Highmore has described as 'a social imaginary made up of mass images that can be treated as dream elements and wish fulfilments of a social unconscious' (2002: 84). Directives continue to ask for imaginative input: to describe yourself as a machine; to record a recent dream; to confide fantasies, lies and secrets; to envisage yourself in the future.

The particular addressivity of the Mass Observers' contributions - solicited and framed by the directive, mirroring of its style and generated in anticipation of a reader - should be interpreted therefore not only for their subject content but also as a product of the relationships that generate it and receive it. Shaw has described the MO archive as 'a 
transitional object or zone where researchers and $\mathrm{M}-\mathrm{O}$ writers meet for their mutual and joint uses' (1998: 6), and Harrison and McGhee (2003) have defined these entwined encounters as intertextual. The multiple perspectives that are brought to bear on $\mathrm{MO}$ and the multiple identities that come into play identify the results as not only subjective but intersubjective in character. The materials that result are not only closely reflective but selfreflexive; they demonstrate not only thick description of the topics under scrutiny but also the process by which such descriptions come to be constructed; finally they reflect on the anticipated readings and uses that may be made of such processes and outcomes. The material is thus highly complex and extraordinarily valuable to a range of researchers, including those who research research. That such an adaptable and nuanced body of material has been solicited and sustained is a considerable achievement on the part of MOP's organisers.

Although intersubjectivity and the shaping of one's communicative acts in relation to the perceived needs of a recipient are part of the everyday relational behaviour, the particular and heightened conditions of the $\mathrm{MO}$ encounter - where exchange is simultaneously restricted and enabled by anonymity and the archival screen - creates a distinctive space where these kinds of performances can be enacted. Through endeavours such as the MIMO project and through directives such as 'Being Part of Research', the purpose and meaning of $\mathrm{MO}$ is subject to heightened scrutiny and the usually unseen intersecting relationships are made visible and even reshaped. As C3086, an engineer from Northumberland, noted, 'I don't think about the people reading this at all. I just started wondering if I should. "Hello" to you if you read this.' $\mathrm{MO}$ also provides a performative site for the mutual shaping of readers and writers, and for challenging the imagined divisions that can exist between categories of 'us' and 'them'. MO's distinctive materials are the result of these sometimes complex interrelationships, reciprocal performances and multiple perspectives. They cannot stand outside of these circumstances and the meanings made of them must acknowledge their conditions.

Black, Alistair and Crann, Melvyn (2001), 'Observed from within', Public Library Journal, 16 (1), 15-16.

Bloome, David, Sheridan, Dorothy , and Street, Brian (1993), Reading Mass Observation Writing: Theoretical and Methodological Issues in Researching the Mass-Observation Archive (Sussex: University of Sussex Library).

Clifford, James (1988), The Predicament of Culture: Twentieth Century Ethnography, Literature and Art (Harvard University Press).

Gillespie, Alex and Cornish, Flora (2009), ' Intersubjectivity: Towards a Dialogical Analysis', Journal for the Theory of Social Behaviour, 40 (1), 19-46.

Goot, Murray (2007), 'Mass-Observation and Modern Public Opinion Research', in Wolfgang Donsbach and Michael W. Traugott (eds.), The Sage Handbook of Public Opinion Research (Sage).

Harrison, Kaeren and McGhee, Derek (2003), 'Reading and writing family secrets: reflections on mass-observation', Auto/Biography, XI (Numbers 1 and 2), 25-36. 
Highmore, Ben (2002), Everyday Life and Cultural Theory (London: Routledge).

Hinton, James (2010), Nine Wartime Lives: Mass Observation and the Making of the Modern Self (Oxford: Oxford University Press).

Hinton, James (2013), The Mass Observers: A History, 1937-1949 (Oxford: Oxford University Press).

Hubble, Nick (2010), Mass Observation and Everyday Life: Culture, History, Theory (London: Palgrave Macmillan).

Pollen, Annebella (2013), 'Research Methodology in Mass Observation Past and Present: 'Scientifically, about as valuable as a chimpanzee's tea party at the zoo'?', History Workshop Journal, (75), 213-35.

Purbrick, Louise (2007), The Wedding Present: Domestic Life beyond Consumption (Aldershot: Ashgate).

Raisborough, Jayne and Bhatti, Mark (2007), 'Women's Leisure and Auto/Biography: Empowerment and Resistance in the Garden', Journal of Leisure Research, 39 (3), 459-76.

Shaw, Jenny (1994), 'Transference and Countertransference in the Mass-observation Archive: An Under-Exploited Research Resource', Human Relations, 47 (11), 1391408.

Shaw, Jenny (1996), 'Surrealism, Mass-Observation and Researching Imagination', in E. Stina Lyon and Joan Busfield (eds.), Methodological Imaginations (London: Macmillan).

Shaw, Jenny (1998), Intellectual Property, Representative Experience and Mass-Observation (University of Sussex: Mass-Observation Archive Occasional Paper No. 9).

Sheridan, Dorothy (1993a), 'Writing for... Questions of representation / representativeness, authorship and audience', in David Barton, et al. (eds.), Ordinary People Writing: The Lancaster and Sussex Writing Research Projects (Centre for Language in Social Life: Working Paper Series), 17-23.

Sheridan, Dorothy (1993b), 'Writing to the Archive: Mass-Observation as Autobiography', Sociology, 27 (1), 27-40.

Sheridan, Dorothy (2010), 'Mass Observation Project Report 2: Responses to the 2010 questionnaire', (Special Collections: University of Sussex).

Sheridan, Dorothy and Holland, Caroline (2003), "A Day in the life: interpreting first-hand accounts from the Mass-Observation Archive", in Bill Bytheway (ed.), Everyday Living in Later Life (Milton Keynes: Open University: Centre for Policy on Ageing).

Sheridan, Dorothy, Street, Brian, and Bloome, David (2000), Writing Ourselves: MassObservation and Literary Practices (Cresskill, New Jersey: Hampton).

Sheridan, Dorothy (ed.), (2012), Possession: Tensions in the creation, care and use of archives, with reference to Mass Observation, ed. Graham Dawson (Memory, Narrative and Histories: Critical Debates, New Trajectories Brighton: University of Brighton).

Stanley, Liz (2001), 'Mass-Observation's Fieldwork Methods', in Paul Atkinson, et al. (eds.), Handbook of Ethnography (London: Sage).

Stanley, Nick (1981), 'The Extra Dimension: A study and assessment of the methods employed by Mass-Observation in its first period 1937-40', (Birmingham Polytechnic).

Swales, Valerie M. (1990), 'Making yourself at home: a study in discourse', in Tim Putnam and Charles Newton (eds.), Household Choices (Middlesex: Middlesex Polytechnic and Futures Publications Ltd). 
